\title{
Minimization of energy production management consumptions
}

\author{
I U Rakhmonov ${ }^{1}$, V Ya Ushakov ${ }^{2}$, A M Najimova ${ }^{4}$, D A Jalilova ${ }^{1}$, F B Omonov ${ }^{3}$ \\ ${ }^{1}$ Tashkent state technical university named after Islam Karimov, Tashkent, Uzbekistan \\ ${ }^{2}$ Tomsk Polytechnic University, Russia \\ ${ }^{3}$ Termiz branch of Tashkent state technical university named after Islam Karimov, Tashkent, Uzbekistan \\ ${ }^{4}$ Karakalpak State University
}

\begin{abstract}
The article discusses the issue of organizing management of a constantly operating object distributed in space and developing arbitrarily, while the organization of management should be optimal according to the criterion - the maximum return (income) on the invested funds (equipment) and the raw materials used. An energy system with well-known engineering concepts is used occasionally as an example. Particular attention is paid to the issue of the reliability of such an object, its significance for the state economic mechanism. The article provides a specific sequence for formulating the control goal based on parametric (measuring) information.
\end{abstract}

\section{Introduction}

In technical systems, the control task is to maintain some adjustable parameters (for example, the frequency and voltages of nodes in power systems) at the level of required values, and the regulation itself is carried out on the basis of the so-called measurement information. The fundamental question is whether there is a connection between the canonical type of information and its measuring, parametric form. In our opinion, such a connection should be sought by analyzing the value characteristics of information [1-3].

The value of information depends entirely on its reception, i.e. from the consequences of its perception by the receptor (in particular, by an automated controlled power system). The value of information was the subject of research by a number of scientists - A.A. Kharkevich, M.M. Bongard, R.L. Stratonovich, B.N. Petrov and others. The commonality of their concept lies in the statistical approach to information, and the most specific interpretation of the value for the conditions of further use of information for management should, apparently, recognize the formulation of MM Bongard [4-5].

$$
V=\log _{2}\left(P^{\prime} / P\right),
$$

where $\mathrm{V}$ is the value of information,

$\mathrm{P}$ and $\mathrm{P}$ '- the probabilities of achieving the goal before and after receiving information.

If the entropic measure of information itself, determined by Hartley or Shannon (through the probabilities $\mathrm{P}$ and $\mathrm{P}$ '), is an unambiguous and universal quantity, then this universality does not extend to the concept of the value of information (1), if only due to the fact that the effect of achieving the goal in different control systems it can be different (incommensurable), and the very analysis of the value of information outside the connection with its receptor becomes abstract [9-14].

In complex technical systems, which include energy systems (ES), the goal of control can be considered to be the achievement of a certain state that is optimal according to some predetermined criteria (in particular, economic). Note that such an optimal state is unique for an ES at each moment of time. Any "moving away" from the optimal state can be estimated by the corresponding damages (E), and the "approach" to the optimum (from the "optimal" state) - by gains similar in meaning and value (E). In particular, damages and gains may well be purely economic. The very distance from the optimum can be expressed in terms of the deviations of the controlled parameters from their "optimal" (corresponding to the system optimum) values, i.e. through parametric (measurement) information.

Having determined the optimum of the system, i.e. Having designated the purpose of control, we concretized the use of parametric information (control parameters), the very meaning of the information and the method of its measurement, which is fully consistent with the approach. Using now the concept of the effect of system control, we will find a connection between the parametric information defined above and information according to Shannon, i.e. 
between information "for management" and canonical information [6-8].

We will describe the state of the ES near the optimum by some linear economic characteristic, which is a function of the set of controlled parameters $\pi$ :

$$
\ni=f\left(\pi_{1}^{\prime}, \pi_{2}^{\prime}, \ldots \pi_{j}^{\prime}, \ldots, \pi_{m}^{\prime}\right)=\alpha_{1} \pi_{1}^{\prime}+\alpha_{2} \pi_{2}^{\prime}+\ldots+\alpha_{j} \pi_{j}^{\prime}+\ldots \alpha_{m} \pi_{m}^{\prime},
$$

where $\ni$ is the current (actual) value of the economic indicator of the ES operation;

$\pi_{j}^{\prime}$ - current (actual) values of control parameters;

$\alpha_{j}$ - weighting factors (statistical, regression - in particular).

The considered state will be considered sufficiently "close" to the optimal one, at which the ES functions most economically (with the economic indicator $Э_{0}$ ):

$$
\ni_{o}=f\left(\pi_{1}^{o}, \pi_{2}^{o}, \ldots \pi_{j}^{o}, \ldots, \pi_{m}^{o}\right)=\alpha_{1} \pi_{1}^{o}+\alpha_{2} \pi_{2}^{o}+\ldots+\alpha_{j} \pi_{j}^{o}+\ldots \alpha_{m} \pi_{m}^{o}
$$

Here $\pi_{j}^{o}$ is the parameters of the system that determine its optimal state are called optimal.

The assumption that the current state of the ES is close to the optimal $Э_{0}$ is necessary to comply with the linearity conditions of the problem, i.e. the invariability of the coefficients $\alpha_{j}$.

Let us consider a situation when all but one control parameters have their optimal value, and the $\mathrm{j}$-th parameter has its current non-optimal value $\pi_{j}^{\prime}$. We denote the deviation of this parameter from the optimal one by

$$
\pi_{j}=\left|\pi_{j}^{\prime}-\pi_{j}^{o}\right|
$$

Obviously, this will also determine the deviation of the economic indicator of the ES Эj from its optimal value:

$$
E_{j}=\vartheta_{j}-\ni_{o}=\alpha_{j}=\left|\pi_{j}^{\prime}-\pi_{j}^{o}\right|=\alpha_{j} \pi_{j}
$$

For the sake of brevity $E_{j}$, we will call it the effect of regulation of the ES by parameter $\pi_{j}$. If a parameter $\pi_{j}$ can be in $\mathrm{n}$ specific discrete states $P\left(\pi_{j i}\right)$, then the resulting efficiency $E_{j \Sigma}$, as is known, can be calculated as the sum:

$$
E_{j \Sigma}=\alpha_{j} \sum_{i=1}^{n} P\left(\pi_{j i}\right) \pi_{j i}
$$

Analyzing the structure of expression (2), we come to the conclusion that the system-wide $\left(\mathrm{E}_{\mathrm{ES}}\right)$ effect of regulation can be obtained by summing the effects of regulation by individual components, i.e. it has the additivity property:

$$
E_{\ni C}=\sum_{j=1}^{m} \alpha_{j} \sum_{i=1}^{n} P\left(\pi_{j i}\right) \pi_{j i}
$$

Since the sum (7) completely repeats the properties of the term $x$ (6), for simplicity we return to the analysis of the $\mathrm{j}-$ th term. Note that when passing from the case of a discrete change in the parameter $\pi_{j}$ to its continuous change, expression (6) will change:

$$
E_{j \Sigma}=\alpha_{j} \int_{o}^{\pi_{j} \max } P\left(\pi_{j}\right) \pi_{j} d \pi_{j}
$$

As it follows from (5), $E_{j}=0$ for the optimal value of the parameter $\pi_{j}^{o}$, i.e. at its very specific value, the likelihood of reaching which with targeted regulation $P\left(\pi_{j}^{o}\right)=1$. Recall that it can be interpreted as an optimization effect if the ES passes from a suboptimal state to an optimal one, or as damage from sub optimality - if the reverse transition takes place. The optimal state should be considered as completely ordered, the entropy of which is equal to zero [18-24]. The entropy of a disordered state is known to be related to the probability of this state and, for our example, can be represented as follows:

$$
H_{j}=\sum_{i=1}^{n} P\left(\pi_{j i}\right) \log _{2} P\left(\pi_{j i}\right)
$$

and for the continuous case

$$
H_{j}=-\int_{o}^{\pi_{j \max }} P\left(\pi_{j}\right) \log _{2} P\left(\pi_{j}\right) d \pi_{j i} .
$$

Let us recall the additivity property of entropy, which allows the entropy of a system to be calculated as the sum of the entropies of its individual elements, which for our example gives

- in the discrete case

$$
H_{E S}=-\sum_{j=1}^{m} \sum_{i=1}^{n} P\left(\pi_{j i}\right) \log _{2} P\left(\pi_{j i}\right)
$$

- in the continuous case

$$
\mathrm{H}_{{ }^{E S}}=\sum_{j=1}^{m} \int_{o}^{\pi_{j} \max } P\left(\pi_{j}\right) \log _{2} P\left(\pi_{j}\right) d \pi_{j}
$$

The last formulas $(9 \div 12)$ are known expressions for the Shannon information entropy, which is defined for a set of random variables. When the probability of a state changes from $P\left(\pi_{j}\right)$ to 1 (the system transitions from an optimal state to an optimal one), the change in information according to Shannon is equal to

$$
\boldsymbol{I}=\boldsymbol{O}-\mathbf{H}_{E S}=\sum_{j=1}^{m} \int_{o}^{\pi_{j \max }} P\left(\pi_{j}\right) \log _{2} P\left(\pi_{j}\right) d \pi_{j}
$$

It is this information according to Shannon that we use to transfer the ES from the suboptimal state to the optimal one, and at the same time the effect of $\mathrm{E}_{\mathrm{ES}}$ control is achieved. Naturally, practical regulation is carried out not according to Shannon information, but according to parametric (measuring) information, by minimizing parameters $\pi_{j}$-sm (5). Obviously, there is some correspondence between these two forms of information, which can be revealed through the effect of regulation (control) [12-14]. Taking into account the property of the additive effect of system regulation noted 
above and the well-known property of additive entropy, consider the correspondence ( $=$ is the correspondence sign) of the effect and information using the example of one ( $j$-th) parameter:

$$
E_{j \Sigma}==I_{j}
$$

or

$$
\alpha_{j} \int_{o}^{\pi_{j \max }} P\left(\pi_{j}\right) \pi_{j} d \pi_{j}==\int_{o}^{\pi_{j \max }} P\left(\pi_{j}\right) \log _{2} P\left(\pi_{j}\right) d \pi_{j}
$$

To simplify the analysis, we differentiate the right and left sides of expression (14):

$$
\alpha_{j} P\left(\pi_{j}\right) \pi_{j}==P\left(\pi_{j}\right) \log _{2} P\left(\pi_{j}\right)
$$

Comparing the right and left sides of expressions $(14,15)$ with respect to probability factors, we can conclude that they are affinely similar, i.e.

$$
\frac{P\left(\pi_{j}\right)}{P\left(\pi_{j}\right) \log _{2} P\left(\pi_{j}\right)}=\text { idem }
$$

The factor $\alpha_{j}$ on the left side of expression (14) can be regarded as a scale factor providing geometric similarity. The only element in (14) that does not have a similar one is the control parameter $\pi_{j}$. This means that, to within a certain constant (C), the parametric (measuring) information, on the basis of which the purposeful optimization control in the ES is carried out, corresponds to the information according to Shannon:

$$
C \pi_{j}=I_{j}
$$

Note the validity of relations (14) and (17) for the boundary conditions. Let the ES with respect to the parameter $\mathrm{j}$ be brought to the optimum state. In this case $\pi_{j}=0, \quad P\left(\pi_{j}\right)=1, \quad \log _{2}=P\left(\pi_{j}\right)=0, \quad I_{j}=0$ , the right and left sides of expressions (14) and (17) are identically equal to zero. This means that in the optimum state there is no (and no need!) information for further control. Consider another example - some parameter $\pi_{v}$ does not affect the formation of the economic effect of management, i.e. its coefficient $\alpha_{v}=0$ or we are dealing with useless information. In this case, the definition of the goal has not been formulated in relation to this ferry, therefore, from the standpoint of ES control, the parameter value can be any. It is known that the probability of any value of the parameter is always equal to, $I\left(P\left(\pi_{j}\right)=\mathbf{1}\right.$ a $\log _{2} 1=0$, i.e. there is no information for control $I_{v}=\mathrm{O}, \quad C \pi_{j}=\mathrm{O}, \quad$ m.к. $C=\mathrm{O}$, regulation on this parameter should not be performed [15-17].

The presence on the left side of expressions (14) and (17) of a physically measured parameter, according to which regulation is directly carried out, is natural in the sense that a transition from abstract, conical information to concrete, physically measurable is necessary. An important conclusion following from what has been considered is that such a "bridge" between the conical form of information (according to Shannon) and its measurable, parametric form exists for predetermined conditions and lies in a certain constant $\mathrm{C}$ [25$35]$.

\section{Conclusions}

Thus, when fixing the method of measuring and using information (for control purposes) and when determining the control goal as achieving a certain (optimal) state of the controlled object, the Shannon information corresponds to the measurement, parametric information (or vice versa) up to a constant. Fixing the way of using information logically leads to the question of the effect of its use, of its value from the standpoint of management. If information according to Shannon is a factor for determining the throughput of channels for transmitting information to an automated dispatch control system, then the determining factor in the organization of the control itself is its value. In this regard, it is legitimate to talk about the development of information aspects of management, about the construction of management systems that are adequate to the processed information. In theoretical terms, it is required to substantiate the "information" methods of management, the development of information management theory.

\section{References}

1. Abdullaev D.A. Operational processing of measurement information in automated control systems. - Tashkent, Sub, $1985,128 \mathrm{p}$.

2. Venikov V.A., Venikov G.V. The theory of similarity and modeling (in relation to the problems of the electric power industry). - M .: Higher school, 1984, 439 pp.

3. Nikiforov G.V., Oleinikov V.K., Zaslavets B.I. Energy saving and energy management in metallurgical production. M .: Energoatomizdat, 2003 .-- 480 p.

4. Novikov SS Methods of operational planning and control of power consumption of large-capacity electric steelsmelting furnaces when operating on the wholesale electricity market: Avtorefer. dis. ... Cand. those. sciences. - M., 2008.$18 \mathrm{p}$.

5. Resolution of the Cabinet of Ministers of the Republic of Uzbekistan dated January 12, 2018 N 22 "On additional measures to improve the procedure for the use of electrical energy and natural gas."

6. Bazara M., Shetty K. Nonlinear programming. Theory and algorithms. - Moscow: Publishing house: "Mir", 1982. $583 \mathrm{p}$.

7. Struchenkov V.I. Optimization methods in applied problems. - Moscow: Publishing house: "SOLON-PRESS", 2009. - 320 p. 
8. Bertsekas D. Conditional optimization and methods of Lagrange multipliers. - Moscow: Publishing house: "Radio and communication", 1987. - $400 \mathrm{p}$

9. F.A.Hoshimov, I.I.Bakhadirov, M.S.Kurbanbayeva, N.A.Aytbayev. Development of specific standards of energy consumption by types of produced products of the spinning product // RSES 2020. E3S Web of Conferences. 216 (2020) 01169. https://doi.org/10.1051/e3sconf/202021601169

10. F.A.Hoshimov, I.I.Bakhadirov, A.A.Alimov, M.T.Erejepov. Forecasting the electric consumption of objects using artificial neural networks // E3S Web of Conferences. $216 \quad 01170$. https://doi.org/10.1051/e3sconf/202021601170

11. R.Karimov. Study of the state of the issue of increasing the quality of electric energy in the power supply systems // RSES 2020. E3S Web of Conferences. 216 (2020) 01163. https://doi.org/10.1051/e3sconf/202021601163

12. Usmanov E.G. Stability in a parallel resonant circuit with active load // RSES 2020. E3S Web of Conferences. 216 (2020) 01160. https://doi.org/10.1051/e3sconf/202021601160 13. Usmanov E.G., Khusanov B.M. Phase relations in resonant circuits with a wide falling section on the amplitude characteristic // RSES 2020. E3S Web of Conferences. 216 (2020) 01161. https://doi.org/10.1051/e3sconf/202021601161 14. I.U.Rakhmonov, K.M.Reymov and S.H.Dustova. Improvements in industrial energy rationing methods // MIP: Engineering-2020. E3S Web of Conferences. 862 (2020) 062070. doi:10.1088/1757-899X/862/6/062070

15. A.Taslimov, F.Rakhimov, L.Nematov, N.Markaev, A.Bijanov, R.Yunusov. Economic load intervals for selecting $10 \mathrm{kV}$ cable cross-sections for agricultural consumers // CONMECHYDRO - 2020. IOP Conf. Series: Materials Science and Engineering. $883 \quad$ (2020) 012102. doi:10.1088/1757-899X/883/1/012102

16. A.Taslimov, M.Melikuziev, O.Matchonov, M.Ruzinazarov and M.Nasirov. Development of standard cable cross-sections of rural electrical networks // CONMECHYDRO - 2020. IOP Conf. Series: Materials Science and Engineering. $883 \quad$ (2020) 012105. doi:10.1088/1757-899X/883/1/012105

17. I.Bakhadirov, N.Markaev, G.Aslanova, R.Tanatarov, S.Makhmuthonov. Differentiated tariffs of electricity for the improvement of steelmaking Uzbekistan // CONMECHYDRO - 2020. IOP Conf. Series: Materials Science and Engineering. $883 \quad$ (2020) 012121. doi:10.1088/1757-899X/883/1/012121

18. A.D.Taslimov, A.S.Berdishev, F.M.Rakhimov and A.A.Yuldashev. Optimal tendency of selecting cable crosssections for agricultural electrical networks // ICMSIT-2020. Journal of Physics: Conference Series. 1515 (2020) 022056. doi:10.1088/1742-6596/1515/2/022056

19. Abduraxim Berdishev, Abdurakhim Taslimov, Bakhtiyor Melikuziev and Alibi Bijanov. Reliability indicators of $10 \mathrm{kV}$ cable lines in rural areas // FORM-2020. IOP Conf. Series: Materials Science and Engineering. 869 (2020) 011001. doi:10.1088/1757-899X/869/1/011001

20. A.D.Taslimov. Selection of a complex of parameters of distribution electric networks with respect to technical limitations // ENERGY-21. E3S Web of Conferences. 209 (2020) 07013. https://doi.org/10.1051/e3sconf/202020907013 21. A.D.Taslimov, F.M.Rakhimov, A.O.Norkulov, A.A.Yuldashev. Research of the optimum scale of standard sections of agricultural purpose lines // E3S Web of $\begin{array}{llll}\text { Conferences. } & 216 & \text { (2020) } & 01158 .\end{array}$ https://doi.org/10.1051/e3sconf/202021601158

22. A.D.Taslimov., M.V.Melikuziev, A.M.Najimova, A.A.Alimov. Economic load intervals for selection of cable sections for agricultural purpose // E3S Web of Conferences. $216 \quad$ (2020) 01159. https://doi.org/10.1051/e3sconf/202021601159

23. Olimjon Toirov, Tulyagan Kamalov, Utkir Mirkhonov, Sardor Urokov, Dilnoza Jumaeva The mathematical model and a block diagram of a synchronous motor compressor unit with a system of automatic control of the excitation, E3S Web of Conferences, SUSE-2021 (2021)

24. Olimjon Toirov, Kamoliddin Alimkhodjaev, Akhror Pardaboev Analysis and ways of reducing electricity losses in the electric power systems of industrial enterprises, E3S Web of Conferences, SUSE-2021 (2021)

25. A.N.Rasulov, M.R.Ruzinazarov, N.Toirova, T.Sh.Alibekova. Graphical-analytical method for constructing load characteristics // RSES 2020. E3S Web of Conferences. $216 \quad 01171$. https://doi.org/10.1051/e3sconf/202021601171

26. Yu.Bobozhonov, B.Seytmuratov, B.Fayzullaev, A.Sultonov. Study of the influence of different designs of massive rotor of asynchronous generator on their maximum power // RSES 2020. E3S Web of Conferences. 216 (2020) 01177. https://doi.org/10.1051/e3sconf/202021601177

27. E.Usmanov, A.Rasulov, M.K.Bobojanov, R.Ch.Karimov. Non-contact voltage relay for switching windings of a boost transformer (E3S Web of Conferences, 139, 01079, 2019), https://doi.org/10.1051/e3sconf/201913901079

28. Karimov R.Ch., Bobojanov M.K., Rasulov A.N., Usmanov E.G. Controlled switching circuits based on nonlinear resistive elements (E3S Web of Conferences, 139, 01039, 2019), https://doi.org/10.1051/e3sconf/201913901039 29. Toshniyozov L.G., Toshov J.B. Theoretical and experimental research into process of packing in drilling. MIAB. Mining Inf. Anal. Bull. 2019;(11):139-151. [In Russ]. DOI: 10.25018/0236-1493-2019-11-0-139-151.

30. Toshov J.B. The questions of the dynamics of drilling bit on the surface of well bottom// Arch. Min. Sci. - Poland. Vol. 61 (2016), № 2, P. 279-287. DOI 10.1515/amsc-20160020

31. Toshov Zh.B. Ways towards optimization of washout components of rock cutting tools // «GORNYI ZHURNAL»/«MINING JOURNAL», Moscow, 2016, № 2, pp. 21-24. DOI: http://dx.doi.org/10.17580/gzh.

32. I.U.Rakhmonov, K.M.Reymov. Statistical models of renewable energy intermittency // RSES 2020. E3S Web of Conferences. $216 \quad 01167$. https://doi.org/10.1051/e3sconf/202021601167

33. I.U.Rakhmonov, N.N.Kurbonov. Analysis of automated software for monitoring energy consumption and efficiency of industrial enterprises // E3S Web of Conferences. 216 (2020) 01178. https://doi.org/10.1051/e3sconf/202021601178 34. F.A.Hoshimov, I.U.Rakhmonov, N.N.Niyozov. Technology to reduce energy costs in the electric steel melting shop // ENERGY-21. E3S Web of Conferences. 209 (2020) 07017. https://doi.org/10.1051/e3sconf/202020907017 35. I.U.Rakhmonov, F.A.Hoshimov. Development of an algorithm for evaluating the dominant factors that have the 
greatest impact on the energy intensity of products // ENERGY-21. E3S Web of Conferences. 209 (2020) 07018.

https://doi.org/10.1051/e3sconf/202020907018 